\title{
Enseñanza híbrida en escuelas de educación básica: percepciones y perspectivas de los maestros
}

\author{
Renata Godinho Soares \\ renatasoares.aluno@unipampa.edu.br \\ http://orcid.org/0000-0002-2386-2020 \\ Universidade Federal do Pampa (UNIPAMPA) \\ Uruguaiana, Brasil. \\ Caroline Pugliero Coelho \\ carolinecoelho.aluno@unipampa.edu.br \\ http://orcid.org/0000-0003-2999-9316 \\ Universidade Federal do Pampa (UNIPAMPA) \\ Uruguaiana, Brasil \\ Eliane de Lourdes Fontana Piffero \\ elianepiffero.aluno@unipampa.edu.br \\ http://orcid.org/0000-0001-7817-3903 \\ Universidade Federal do Pampa (UNIPAMPA) \\ Uruguaiana, Brasil \\ Jaqueline Copetti \\ jaquelinecopetti@unipampa.edu.br \\ https://orcid.org/0000-0003-4838-1810 \\ Universidade Federal do Pampa (UNIPAMPA) \\ Uruguaiana, Brasil
}

Recibido: 31/março/2021 Aceptado: 01/setembro/2021

\section{Resumen}

Se vive un escenario diferenciado en el contexto educativo debido a la pandemia Covid-19. La enseñanza híbrida ha sido aplicada por varios ámbitos de la enseñanza, ya que en este momento, es el modelo que más contempla las necesidades educativas de los alumnos. En este sentido, el objetivo de este estudio era analizar las percepciones de los profesores sobre la implementación de la educación híbrida en las escuelas municipales en la frontera occidental de Rio Grande do Sul (RS, Brasil). En la investigación caracterizada como cualitativa, exploratoria y descriptiva, participaron 77 profesores de educación básica asignados en 3 escuelas del sistema escolar municipal de 2 municipios del interior de RS. A partir de tres encuentros formativos, uno en cada escuela, los profesores respondieron a un cuestionario con preguntas cerradas y abiertas con el fin de entender la realidad de la enseñanza actual y las percepciones sobre la implementación de la enseñanza híbrida en el futuro. El análisis de contenido y la teoría de datos en tierra se utilizaron para el análisis de datos. Se considera, según la percepción del profesorado, que la implantación de la enseñanza híbrida es factible dentro de las realidades escolares de éstas, ya que puede permitir una mayor aproximación entre profesor y alumno, además de oportunista diferentes métodos de enseñanza.

Palabras clave: Metodologías activas. Tecnologías. Formación de profesores. 


\title{
Ensino Híbrido em escolas da educação básica: percepções e perspectivas de professores
}

\begin{abstract}
Resumo
Vivencia-se um cenário diferenciado no contexto educacional em decorrência da pandemia da Covid-19. O ensino híbrido vem sendo aplicado por diversas esferas de ensino, pois nesse momento, é o modelo que mais contempla as necessidades educacionais dos alunos. Nesse sentido, o objetivo deste estudo foi analisar as percepções de professores sobre a implementação do ensino híbrido em escolas municipais da fronteira oeste do Rio Grande do Sul (RS, Brasil). A pesquisa caracterizada como qualitativa, de caráter exploratório e descritivo, envolveu 77 professores da educação básica alocados em 3 escolas da rede municipal de ensino de 2 municípios do interior do RS. A partir de três encontros formativos, um em cada escola, os professores responderam um questionário com questões fechadas e abertas com o objetivo de entender a realidade de ensino atual e as percepções sobre a implementação do ensino híbrido futuramente. Para análise dos dados utilizou-se da Análise de Conteúdo e a Teoria Fundamentada de Dados. Considera-se, de acordo com as percepções dos professores, que a implementação do ensino híbrido é viável dentro das realidades escolares destes, visto que o mesmo pode possibilitar uma maior aproximação entre professor e aluno, além de oportunizar diferentes métodos de ensino.
\end{abstract}

Palavras chave: Metodologias ativas. Tecnologias. Formação de professores.

\section{Blended learning in basic education schools: teachers' perceptions and perspectives}

\begin{abstract}
A differentiated scenario is experienced in the educational context due to the Covid-19 pandemic. The blended learning has been applied by several spheres of teaching, because at this moment, it is the model that most contemplates the educational needs of students. In this sense, the aim of this study was to analyze the perceptions of teachers about the implementation of hybrid education in municipal schools on the western border of Rio Grande do Sul (RS, Brazil). The research characterized as qualitative, exploratory and descriptive, involved 77 basic education teachers allocated in 3 schools of the municipal school system of 2 municipalities in the interior of RS. From three formative meetings, one in each school, the teachers answered a questionnaire with closed and open questions in order to understand the reality of current teaching and perceptions about the implementation of hybrid teaching in the future. Content Analysis and Grounded Data Theory were used for data analysis. It is considered, according to the perceptions of teachers, that the implementation of hybrid teaching is feasible within the school realities of these, since it can enable a greater approximation between teacher and student, besides opportunistic different teaching methods.
\end{abstract}

Keywords: Active methodologies. Technologies. Teacher training.

\section{Introdução}

Diante das demandas cada vez mais complexas, o processo de ensino e aprendizagem precisa acompanhar as transformações do mundo contemporâneo. Sendo assim, cada vez mais fala-se sobre o ensino híbrido, uma tendência da educação atual, integrando o ensino presencial com propostas também de ensino online. Essa combinação foi caracterizada por Christensen, Horn, Staker (2015), como Ensino Híbrido (EH) do inglês Blended Learning, 
que busca combinar o ensino de forma tradicional de sala de aula com novas abordagens educacionais e tecnológicas (SCHIEHL; GASPARINI, 2017).

O ensino híbrido já é uma realidade nos Estados Unidos e na Europa como uma possibilidade para resolver o problema da evasão escolar dos alunos de cursos à distância, gerada pela sensação de abandono sentida por estes (BRITO, 2020). No Brasil, essa modalidade de ensino já é realizada em Instituições de Ensino Superior (IES) há algum tempo. Na educação básica, a partir da lei da Lei n ${ }^{\circ}$ 14.040, de 2020, que dispõe sobre a adoção de atividades pedagógicas não presenciais (o ensino remoto), durante o período de calamidade pública decretado em decorrência da pandemia do coronavírus, a possibilidade de sua utilização ficou em evidência.

Para a implementação do EH, há a necessidade de transformar o papel dos professores, onde estes passarão a mediar a trajetória de aprendizagem do aluno, que se tornará um eterno aprendiz, habilidade necessária nos tempos em que vivemos, devido suas constantes mudanças, no qual as informações tornam-se obsoletas rapidamente (HORN; STAKER, 2015, p.33). Bacich et al. (2015) destacam a importância do papel do professor na organização e no direcionamento do processo, que exige planejamento de atividades que possam atender às demandas reais da sala de aula, identificando a necessidade de que o processo de ensino-aprendizagem ocorra de forma colaborativa, com foco no compartilhamento de experiências e na construção do conhecimento a partir das interações com o grupo.

Essa nova postura do professor revela a importância de uma formação permanente, uma vez que o docente precisa estar atualizado e preparado para incorporar metodologias ativas com o apoio das tecnologias digitais em sala de aula (MORAIS; SOUZA, 2020). Segundo Moran (2015) o modelo de EH contemplado com metodologias ativas e tecnologias digitais pode promover um currículo mais flexível, sem rigidez e engessamento de planejamento. O autor supracitado complementa que, no cenário do EH, "um bom professor pode enriquecer materiais prontos com metodologias ativas: pesquisa, aula invertida, integração na sala de aula e atividades on-line, projetos integradores e jogos" (MORAN, 2015, p. 36).

Segundo Neto (2017) a atualização constante do professor mostra-se crucial para o bom desempenho dos alunos e para que o processo de ensino-aprendizagem ocorra com qualidade. Evidenciando-se as mudanças impostas pela pandemia, e tendo o EH como uma das alternativas mais viáveis para um retorno escolar presencial gradual, o objetivo deste 
estudo foi analisar as percepções dos professores sobre a implementação do ensino híbrido em escolas municipais da fronteira oeste do RS.

\section{Metodologia}

O presente estudo caracteriza-se como uma pesquisa qualitativa, de caráter exploratório e descritivo em seu desenvolvimento. Segundo Gil (2010), a pesquisa exploratória busca familiarizar-se com um assunto ainda pouco conhecido ou pouco explorado. O referido autor ressalta ainda que "[...]pesquisas descritivas, têm como objetivo primordial a descrição das características de determinada população" (p.27).

Foram sujeitos desta pesquisa, 77 professores da Educação Básica (Educação Infantil, Ensino Fundamental) alocados em 3 escolas da rede municipal de ensino de 2 municípios do interior do Rio Grande do Sul. Quanto ao contexto das escolas, 2 das escolas possuem alunos desde a Educação Infantil até os anos finais do Ensino Fundamental, comportando cada uma em torno mil alunos atendidos. A terceira escola possui alunos da Educação Infantil até os anos iniciais do Ensino Fundamental e atende em média 200 alunos.

Ainda, quanto recursos digitais para as aulas, as escolas possuem: internet banda larga, televisores, aparelhos projetores multimídia e caixas de som. Durante a pandemia os professores fizeram uso de aparelhos celulares e notebooks arcados com investimento pessoal, houveram relatos de professores que tiveram que aumentar a velocidade da internet em casa, alguns inclusive tiveram que comprar aparelhos novos pois os que possuíam já eram obsoletos e não comportavam as demandas urgentes, acarretadas pelo uso de tecnologias digitais na pandemia.

A escolha das escolas se deu de forma intencional, sendo que, houve a procura por parte da gestão de uma das escolas para que as pesquisadoras possibilitassem primeiramente um encontro formativo que abordasse a temática "Ensino Híbrido". A partir desta primeira escola, outras duas escolas buscaram as pesquisadoras para replicar a mesma ação formativa em seus contextos.

Previamente, de modo a construir um encontro formativo que fosse condizente com os anseios dos professores, foi organizado um questionário online, via google formulários, com questões fechadas sobre o perfil dos professores e demais questões referentes ao contato dos professores com os alunos ao longo do ano de 2020, conhecimento dos professores sobre Metodologias Ativas, Tecnologias de Informação e Comunicação (TICs), Ensino Híbrido, além das percepções destes sobre a implementação, pontos positivos e negativos sobre o 
Ensino Híbrido. Este instrumento foi disponibilizado aos professores, via grupo de WhatsApp da própria escola na semana anterior a formação, sendo solicitado que preenchessem o mesmo até o dia anterior a formação.

Este encontro formativo foi pensado em 4 momentos: $1^{\mathrm{o}}$ momento - alguns conceitos (educação à distância, ensino remoto, tecnologias da informação e comunicação e ensino híbrido); $2^{\circ}$ momento - Ensino Híbrido (O que é? Quais seus objetivos? Metodologias ativas no $\mathrm{EH}) ; 3^{\circ}$ momento - modelos de EH na educação básica, a partir das condições dos contextos; $4^{\mathrm{o}}$ momento - tutorial sobre a ferramenta Mentimeter. $\mathrm{O}$ encontro aconteceu através de uma plataforma de reuniões online, onde foi possível gravar o mesmo e também armazenar o bate-papo deste para futura análise.

Cabe diferenciar os termos: Metodologias Ativas, que possuem um conceito de educação crítico-reflexiva baseada em estímulos no processo ensino-aprendizagem, que resulta no envolvimento por parte do educando na construção do seu conhecimento (MACEDO et al., 2018); quanto às Tecnologias da Informação e Comunicação, estas são ferramentas que auxiliam no desenvolvimento de atividades humanas, garantindo a informação e comunicação, independente do meio (HUANG et al., 2019); por fim a Tecnologia Digital da Informação e Comunicação que está ligada aos meios digitais de informar e comunicar o desenvolvimento de atividades humanas (SCORSOLINI-COMIN, 2014).

Fez-se a recolha de todo material (gravações, bate-papos, questionário inicial, nuvem de palavras e comentários recebidos por parte dos professores via Whatsapp) oriundo das 3 formações. Para a análise dos dados, as respostas fechadas foram dispostas conforme frequência de ocorrência, e as respostas abertas (descritivas) foram analisadas com base na análise de conteúdo de Bardin (2016), que consiste na pré-análise, fase de operacionalização e sistematização das ideias iniciais; na exploração do material, onde ocorre a codificação, decomposição ou enumeração; e no tratamento dos resultados, na inferência e na interpretação, visando resultados significativos e válidos para descrever as percepções dos professores sobre ensino híbrido e sua possível implementação.

De forma a complementar a análise e sustentar as percepções dos professores, empregou-se a Teoria Fundamentada nos Dados (TFD) que, para Charmaz (2009), os elementos da TFD têm por princípio a construção de hipóteses ou relações geradas entre as categorias emergentes e suas propriedades. Este método, a partir do escrutínio do objeto de estudo, permite a construção de novas teorias ou conceitos à área do fenômeno estudado. 


\section{Resultados e Discussão}

Os resultados da pesquisa serão apresentados em subtópicos: perfil dos professores, comunicação professor x aluno no ano de 2020, conhecimento sobre TICs, metodologias ativas e EH, implementação e pontos positivos e negativos do ensino híbrido.

\section{Perfil dos docentes}

O perfil dos docentes aponta idade entre 31 e 64 anos, com média de 46 anos. O tempo de docência dos professores variou entre o mínimo de 1 ano e o máximo de 35 anos, com17 anos de média. Sobre o nível de ensino em que atuam 53,2\% dos participantes são docentes dos anos finais do ensino fundamental, 40,3\% docentes dos anos iniciais do ensino fundamental e $6,5 \%$ docentes da educação infantil. A carga horária total dos professores variou de $20 \mathrm{~h}$ a $60 \mathrm{~h}$ semanais, sendo que a maioria dos professores $(63,6 \%)$ possui carga horária de $20 \mathrm{~h}$ na escola em que aconteceu a formação e $52 \%$ dos professores possui atuação de $20 \mathrm{~h}$ em outra escola, em sua maioria. O nível de formação dos professores vai do magistério ao doutorado, sendo que $67,5 \%$ possuem especialização, nas mais diversas áreas do ensino e educação.

Sobre a carga horária dos professores em mais de uma escola, um estudo realizado pelo Ministério da Educação, publicado em 2018, revelou um número considerável de professores (40\%) lecionando em duas ou mais escolas (BRASIL, 2018). Ainda, o estudo de Soares e Copetti (2020) apontou resultados semelhantes. De acordo com as autoras e em consonância um levantamento realizado pelo Instituto de Pesquisa Econômica Aplicada (IPEA, 2017), o translado e envolvimento docente em cada uma das instituições são fatores que dificultam o planejamento e a atuação docente.

Ao observar a relação entre a atuação docente em mais de uma escola e os investimentos na educação básica, uma possibilidade de auxílio na melhoria deste cenário seria o investimento fundamental. O professor quando valorizado, financeiramente e humanamente, poderá tornar-se mais efetivo no exercício da sua profissão e, assim, gerar maiores ganhos com relação ao objetivo principal da educação, o aprendizado do aluno (SOARES; COPETTI, 2020). Percebe-se, com base na literatura que a atuação em mais de uma escola é um fator dificultante da implementação do ensino híbrido, pois causará, em algum ponto a sobrecarga do professor, que atenderá realidades distintas, e para tanto deverá traçar caminhos e planejamentos também distintos. 
Sobre a formação docente, a partir da análise do perfil dos professores participantes da pesquisa, que tem uma média de 17 anos desde a sua formação inicial, considera-se que nesta não houve aproximação com tecnologias digitais, o que reforça a necessidade de constantes formações que contemplem essa temática. Nos achados de Silva (2014, p. 92) diversos professores visualizam as possibilidades de trabalhar com o uso de tecnologias como recursos pedagógicos, mas apontam que a falta de formação continuada "dificulta conceber as tecnologias como instrumentos mediadores no processo de ensino aprendizagem".

\section{Comunicação com os alunos e entrega dos materiais de aula}

As aulas no ano de 2020, e neste início de 2021 se caracterizaram pela entrega das atividades impressas aos alunos, que foram retiradas nas escolas investigadas (quinzenal ou mensalmente). O contato com as famílias, manejo e orientação das atividades para os alunos se deu através das redes sociais e tecnologias de informação e comunicação. A ferramenta mais utilizada, segundo os relatos dos professores, foi o aplicativo de mensagens WhatsApp, alguns ainda apontaram o uso do Facebook. O professor n.56 relatou o seguinte: "Procurei manter sempre o contato pelo grupo whats, através de chamadas de vídeos, realização de lives sempre buscando a interação entre professor - aluno".

A utilização do WhatsApp, como ferramenta de auxílio ao ensino, ao longo da pandemia é evidente. Trata-se de uma ferramenta de comunicação popular, de fácil acesso e não necessita de cadastro prévio, pois já está conectado ao número do telefone celular. Além disso, a ferramenta proporciona o compartilhamento de mensagens no formato de textos, imagens, áudios e vídeos (SILVA; VILHEGAS, 2013). Porém, sabe-se que não é suficiente criar grupos no WhatsApp para discutir o conteúdo dado em sala de aula, ou enviado de forma impressa, é necessário, também, fomentar o interesse dos alunos e procurar estratégias para atender aqueles alunos que não têm acesso ao ensino remoto (FARIAS, 2020).

Ainda sobre a interação entre professor e aluno no período de aulas remotas, um professor chama a atenção para a dificuldade dos alunos ao acesso às tecnologias: Professor n.20 "De forma muito restrita pois a maioria dos alunos não possui internet para haver comunicação entre professor e alunos". Esse relato é frequente na realidade investigada, pois a maior preocupação dos professores, além do contágio com o vírus, se dá pela dificuldade que os alunos têm de acessar a internet. 
Segundo dados de uma pesquisa realizada em 2019 (TIC DOMICÍLIOS, 2019), o acesso a equipamentos de Tecnologias da Informação e Comunicação (TIC) no Brasil é limitado. Apenas $67 \%$ dos domicílios brasileiros possuem acesso à internet, e nas classes D e E, os números chegam a apenas $40 \%$ da população. Ainda, de acordo com a pesquisa, o dispositivo mais utilizado é o celular, utilizado por $84 \%$ das pessoas nas classes D e E, já o uso de computadores é de apenas 9\%, nesta mesma classe (CGI, 2019).

\section{Conhecimento sobre Tecnologias de Informação e Comunicação}

Sobre o nível de acesso dos docentes em relação às tecnologias de informação e comunicação, obteve-se níveis bem diversificados de respostas: 47\% apontou ter pouco acesso às tecnologias, enquanto $34 \%$ relatou ter muito acesso, porém com dificuldade de utilização, devido ao pouco conhecimento sobre as ferramentas possíveis e suas aplicações. Ainda $18 \%$ relatou ter muito acesso e não apontou dificuldades de utilização e, apenas, $1 \%$ relatou não possuir nenhum acesso.

Cabe salientar que ao mencionar-se Tecnologias da Informação e Comunicação (TIC), estas englobam a utilização de tecnologias para auxiliar no desenvolvimento de atividades humanas, sejam elas para o público em geral ou institucional, ligadas à informação, ao processamento, ao armazenamento e à disseminação de informações (HUANG et al., 2019).

Ao se abordar as TICs refere-se desde o uso da comunicação verbal, uso de quadro branco e giz, até a utilização de ferramentas digitais. Quando faz-se uso do termo Tecnologias Digitais de Informação e Comunicação (TDIC), estas relacionam-se apenas aquelas ferramentas ligadas aos meios digitais. Segundo Scorsolini-Comin (2014), as TDIC têm sido cada vez mais discutidas na área da educação em termos de sua adoção nos meios educacionais e de sua possibilidade de agilizar, facilitar e promover novas leituras de mundo em escolas e universidades.

Quando questionados sobre as tecnologias de informação e comunicação conhecidas, os professores relataram com maior frequência: Celular, WhatsApp e Computador, outros itens como Vídeo, E-mail, Facebook e Internet também foram frequentes. O uso de redes sociais como o WhatsApp e Facebook tem a intenção de potencializar efeitos de aprendizados em sala de aula, visto que ambos são amplamente utilizados pelos alunos, tanto do ensino público quanto do privado (JULIANI et al., 2012). 
A adesão para com estas ferramentas faz com que a participação seja grande e o aprendizado amplamente difundido. Manca (2020) em seu estudo já demonstrou o efeito das redes sociais em tempos comuns e os docentes acreditam em uma maior potencialização do efeito das redes sociais nestes momentos de pandemia. Silva et al. (2020) notaram que ao utilizar o WhatsApp para envio de material ao invés do Google Classroom, o retorno foi o dobro, comparando ambas ferramentas. Os autores supracitados destacam que isso ocorre por causa da maior familiarização dos alunos, professores e pais com esse aplicativo que não possui uma única função de interatividade, diferente da plataforma do Google que é destinada para fins educativos.

Percebe-se a relação que os professores fazem dos meios digitais ao se referir às tecnologias de informação e comunicação. Nesse contexto, as Tecnologias Digitais de Informação e Comunicação (TDIC), que podem ser extremamente úteis como ferramentas cognitivas, e desempenhar diferentes papéis nos processos de ensino. As TDIC podem ser utilizadas na educação a distância, no uso de software do tipo simulação, na construção de narrativas digitais, e na implantação da abordagem híbrida de ensino e de aprendizagem, conhecida como a sala de aula invertida (VALENTE, 2014).

Com relação as dificuldades dos professores sobre utilizar TICs, Pontes e Barboza (2021) demostram que, a formação inicial e continuada, fazem-se necessárias na atuação do professor com relação à integração das tecnologias em sala de aula. Os dados demostram também que, na maioria dos casos a falta de recursos, apoio, infraestrutura são fatores que contribuem para a baixa frequência de utilização de tecnologias na escola.

Não obstante, Gonçalves e Kanaane (2021) reafirmam que a formação dos professores, facilita o amadurecimento dos docentes, tornando o processo de aprendizagem eficaz, além de professores sensíveis e humanos que possam valorizar mais a busca do que o resultado pronto, estimulando e apoiando a crítica, estabelecendo formas democráticas de pesquisa e de comunicação. Ainda, a tecnologia digital aproxima professores e alunos, mas em contrapartida deve ser utilizada como forma de agregar o conhecimento, não apenas para sanar dúvidas que possam surgir.

\section{Conhecimento sobre Metodologias Ativas de aprendizagem}

Quando questionados sobre o conhecimento de metodologias ativas de aprendizagem a grande maioria $(88,3 \%)$ assinalou ter pouco conhecimento, mas querer melhorar, aprimorar sua aprendizagem através da formação. Uma porcentagem mínima, 3,9\%, respondeu como 
tendo muito conhecimento sobre metodologias ativas de aprendizagem. O quadro 1, mostra as categorias criadas a partir da análise de conteúdo para a questão referente a este tema.

Quadro 1: Categorização das respostas abertas sobre Metodologias de Aprendizagem

\begin{tabular}{|c|l|c|}
\hline Categoria & \multicolumn{1}{|c|}{ Descrição } & \% (N=77) \\
\hline Protagonismo & $\begin{array}{l}\text { Metodologia cujo objetivo principal é desenvolver a autonomia e o } \\
\text { protagonismo do aluno dentro do seu processo de aprendizagem. }\end{array}$ & $50,66 \%$ \\
\hline $\begin{array}{c}\text { Estratégias e } \\
\text { Ferramentas }\end{array}$ & $\begin{array}{l}\text { Metodologias que utilizam diversificadas estratégias e ferramentas no } \\
\text { processo de ensino-aprendizagem. }\end{array}$ & $25,33 \%$ \\
\hline $\begin{array}{c}\text { Aprendizagem } \\
\text { Significativa }\end{array}$ & $\begin{array}{l}\text { Metodologias que buscam efetivamente a aprendizagem significativa do } \\
\text { aluno. }\end{array}$ & $8 \%$ \\
\hline $\begin{array}{c}\text { Sem Conhecimento } \\
\text { Não conceituaram, relatos de falta de conhecimento sobre o método. }\end{array}$ & $8 \%$ \\
\hline $\begin{array}{c}\text { Ensino Híbrido ou } \\
\text { Online }\end{array}$ & $\begin{array}{l}\text { Metodologias utilizadas apenas em aulas online e/ou no modelo de ensino } \\
\text { híbrido. }\end{array}$ & $5,33 \%$ \\
\hline Práticas em Grupo & Metodologias que envolvam apenas práticas em grupos. & $1,33 \%$ \\
\hline Organização & Organização individual do aluno para com sua aprendizagem. & $1,33 \%$ \\
\hline
\end{tabular}

Fonte: as autoras (2021)

Pode-se observar que boa parte dos docentes fez a relação entre o protagonismo do aluno como base para aplicação das metodologias ativas. Bacich e Morán (2018, p. 80) explicam que "as metodologias ativas constituem alternativas pedagógicas que colocam o foco do processo de ensino e de aprendizagem no aprendiz, envolvendo-o na aprendizagem por descoberta, investigação ou resolução de problemas". Corrobora com essa perspectiva Mitre et al. (2008) quando afirmam que o desenvolvimento e aplicação das metodologias ativas estimulam a busca pelo conhecimento por parte do aluno, promovendo uma aprendizagem ativa e envolvendo-o no processo como um todo.

A segunda maior porcentagem das categorias estabelecidas, apontou que os docentes conceituam metodologias ativas de ensino como aquelas que utilizam diversificadas estratégias e ferramentas no processo de ensino e aprendizagem. As metodologias ativas, quando utilizadas dentro de um contexto, com planejamento embasado por parte do professor, tem alto potencial para despertar a curiosidade dos alunos, favorecendo o desenvolvimento da autonomia, sendo a aprendizagem uma consequência dessas ações (BERBEL, 2011). Piffero et al. (2020) afirmam que as metodologias ativas, aquelas que buscam uma participação ativa dos alunos, são de extrema importância, pois promovem aprendizagem significativa e senso colaborativo dos alunos. 
É notável que a grande maioria dos docentes consegue fazer uma boa relação de conceitos sobre metodologias ativas, mesmo que desconexo e sem uma construção sólida teórica, já conseguem assinalar as bases para aplicação dessas metodologias. Moran (2018, p. 01) explica que "as metodologias ativas são caminhos para avançar mais no conhecimento profundo, nas competências socioemocionais e em novas práticas”.

\section{Conhecimento sobre Ensino híbrido}

Em relação ao nível de conhecimento sobre o EH evidencia-se que a maioria dos professores apresentam pouco conhecimento $(89,6 \%)$, mas demonstram querer aprender mais (76,6\%). Quando questionados sobre o que entendiam sobre o Ensino Híbrido a grande maioria dos professores relacionaram a integração do ensino presencial com o online. A partir da análise das respostas abertas surgiram três categorizações: Momentos Pedagógicos (89,2\%), descrita como a mescla de momentos pedagógicos de forma presencial, remotos e online no decorrer do período letivo; Utilização de Diversas Plataformas (5,8\%) descrita como metodologia de ensino onde é possível a utilização de diversas plataformas digitais, bem como explorar as tecnologias através da internet; e Diversificação de Metodologias (5\%) descrita como a possibilidade de utilização de metodologias diversificadas e diferenciadas.

Percebeu-se que, é destacado o principal diferencial do EH, a mescla entre ensino presencial e ensino remoto. Segundo Moran (2015, p. 27) "híbrido significa misturado, mesclado, blended", na visão do autor o ensino sempre foi híbrido, pois sempre aconteceu em diversos espaços, tempos e atividades, ainda explica que "híbrido é um conceito rico, apropriado e complicado. Tudo pode ser misturado, combinado". Segundo Bacich et al. (2015, p. 43) o modelo de EH, muito utilizado em escolas de educação básica dos Estados Unidos da América, é definido como "modelo em que o método tradicional, presencial, se mistura com o ensino a distância e, em alguns casos, determinadas disciplinas são ministradas na forma presencial, enquanto, outras, apenas on-line”.

De acordo com Valente (2014) existem quatro definições de modelos de EH, são eles: modelo flex, modelo blended, modelo virtual enriquecido e modelo rodízio, cada um possui características específicas que os conceituam e diferenciam. Independente dessas diferenciações quanto aos modelos, cabe ressaltar que o EH busca unir as características da escola tradicional com novas perspectivas vinculadas às tecnologias virtuais, ou seja, espaços físicos com espaços virtuais. Também se mesclam as metodologias e os recursos, 
visando práticas inovadoras e um processo de transformação (RODRIGUES, 2015; SPINARDI; BOTH, 2018). Ainda Schneider (2015, p. 60) afirma que "uma das características do ensino híbrido é o desenvolvimento da autonomia do aluno".

Dentre as respostas sobre EH, alguns verbos foram recorrentes (Figura 2), misturar, mesclar, combinar, alternar. Tais verbos remetem ao principal diferencial dessa modalidade de ensino.

Figura 2: Recorrência de verbos que remetem ao EH, de acordo com os professores.

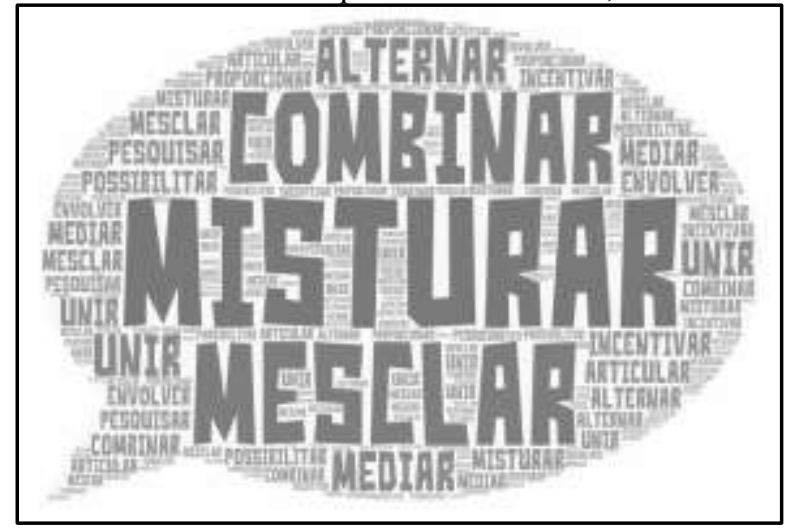

Fonte: das autoras, elaborado em wordart.com (2021).

As palavras utilizadas pelos professores para descrever o que conheciam sobre o $\mathrm{EH}$, veio de encontro com os conceitos já conhecidos, descritos e referenciados por pesquisadores deste modelo de ensino. Masetto (2010, p. 175) conceitua que "o papel do professor em uma aula é o de mediação pedagógica". Os diversos conceitos de EH utilizam verbos como "combinar, misturar ou mesclar" para descrever suas características. Autores como Souza et al. (2019), Novais (2017) e Moran (2015) descrevem o ensino híbrido como a mescla de métodos de ensino-aprendizagem presenciais e virtuais.

Conforme Moran (2015, p. 29), ao falar dos métodos didáticos utilizados no EH, afirma que deve haver um "respeito ao ritmo e estilo de aprendizagem de cada aluno combinado com metodologias ativas grupais". Podemos notar que os conceitos apresentados pelos professores vão de encontro com as principais características do modelo híbrido de ensino. Segundo Bacich et al. (2015, p. 43) "o ensino híbrido configura-se como uma combinação metodológica que impacta na ação do professor em situações de ensino e na ação dos estudantes em situações de aprendizagem".

Destarte, o Ensino Híbrido vai muito além de apenas "misturar" práticas de ensino digitais e presenciais, nesta modalidade de ensino múltiplos fatores são envolvidos, e uma prática não deve ser dissociada da outra e sim, uma complementar a outra. "Noutras 
palavras, é preciso fazer a triagem de conteúdos e definir ações pedagógicas que possam dar conta da "fusão" entre o virtual e o presencial" (BRITO, 2020).

\section{Implementação do Ensino Híbrido x aprendizagem dos alunos}

Quanto a possível implementação do $\mathrm{EH}$ na rede de ensino dos professores investigados, a maioria considera viável sua execução devido a possibilidade de trabalhar a autonomia do estudante, além de proporcionar momentos presenciais para ter o aluno mais próximo e sanar dúvidas. No quadro 3, estão dispostas as respostas e justificativas para a questão referente a implementação do EH.

Quadro 3: Síntese das respostas abertas sobre implementação do Ensino Híbrido

\begin{tabular}{|c|l|c|}
\hline Resposta & \multicolumn{1}{|c|}{ Justificativa } & $\%$ (N=77) \\
\hline Sim & $\begin{array}{l}\text { autonomia do aluno; presencial para sanar dúvidas; contato mais próximo do aluno; } \\
\text { alguns colocam como processo pós pandemia x outros colocam como processo } \\
\text { necessário durante a pandemia; }\end{array}$ & $62,3 \%$ \\
\hline Talvez & $\begin{array}{l}\text { aluno sem acesso à internet; professor sem capacitação às ferramentas digitais x } \\
\text { educação precisa de mudanças; nunca desenvolveu esse tipo de ensino; necessidade } \\
\text { de avaliação contínua sobre as estratégias utilizadas; } \\
\text { insegurança por falta de vacina; }\end{array}$ & $23,4 \%$ \\
\hline Não & $\begin{array}{l}\text { alunos sem acesso à internet; falta de estrutura escolar; maior capacitação } \\
\text { profissional; falta de apoio da família para desenvolver as atividades em casa; } \\
\text { dificuldade de aprendizagem dos alunos; }\end{array}$ & $14,3 \%$ \\
\hline
\end{tabular}

Fonte: das autoras (2021).

Dentre a análise das respostas afirmativas sobre a implementação do $\mathrm{EH}$, alguns professores ainda consideram ser um processo que se estenderá após a pandemia (4\%), em contrapartida outros relatam ser necessário apenas durante a pandemia (10\%). Este é um dado que chama a atenção pois percebe-se há algum tempo a necessidade de mudanças na forma com que são dispostos os processos de ensino-aprendizagem.

Essa reflexão condiz com o pensamento de Almeida et al. (2019), que relatam as inúmeras mudanças tanto em relação a disponibilidade, metodologias de ensino e avaliação. Os referidos autores complementam que o processo de ensino-aprendizagem tem demonstrado a necessidade de refletir sobre as práticas e ferramentas educativas adotadas. Foureaux et al. (2018) observam que no âmbito escolar, de maneira geral, há metodologias de ensino pouco condizentes com os sujeitos que o frequentam, os quais se encontram imersos na era digital. 
Embora existam limitações formativas quanto a utilização de metodologias ativas e tecnologias digitais em sala de aula, reforça-se a necessidade de uma constante atualização profissional, oferecida por parte das mantenedoras educacionais, de forma gratuita e obrigatória, com vistas a minimizar as dúvidas, os anseios, inseguranças e ainda trazer novidades para o contexto escolar (MORAIS; SOUZA, 2020).

Ainda sobre a formação realizada, foi importante, inicialmente, abordar conceitos como Ensino a distância e Ensino remoto, além do Ensino Híbrido. Pois percebe-se um desconhecimento e, por vezes, confusão entre os temas, visto que o Ensino a distância (EaD), segundo o decreto $n^{\circ} 9.057$ (BRASIL, 2017, p. 3) se caracteriza como uma:

[...] modalidade educacional na qual a mediação didático-pedagógica nos processos de ensino e aprendizagem ocorre com a utilização de meios e tecnologias de informação e comunicação, com pessoal qualificado, com políticas de acesso, com acompanhamento e avaliação compatíveis, entre outros, e desenvolva atividades educativas por estudantes e profissionais da educação que estejam em lugares e tempos diversos[...].

Quanto ao Ensino Remoto, Garcia et al. (2020) o consideram como o compartilhamento de conteúdo escolar em aulas organizadas por meio de perfis. Hodges et al. (2020) explicam que o objetivo do ensino retomo emergencial (implementado durante a pandemia) não está em recriar um sistema educacional robusto, mas proporcionar um acesso temporário e suporte a conteúdos educacionais de uma forma fácil e rápida.

O Ensino Remoto de Emergência (ERE) é uma mudança temporária para um modo de ensino alternativo devido a circunstâncias de crise. Envolve o uso de soluções de ensino totalmente remotas para o ensino que, de outra forma, seriam ministradas presencialmente ou como cursos híbridos, e, que, retornarão a esses formatos assim que a crise ou emergência diminuir ou acabar. (HODGES et al., 2020, p. 06)

Logo, ao ser discutido o tema $\mathrm{EH}$, foi importante salientar alguns pontos como: quando e por que surgiu, deixar claro que não é uma modalidade de ensino nova, visto que desde o ano de 2013, os estudos de Christensen et al. (2015) apontavam esta forma de ensino.

Ainda, juntamente ao $\mathrm{EH}$, falou-se sobre a utilização de metodologias ativas, visto que alguns autores (MORAN 2015; BACICH; MORAN, 2018) já citados anteriormente destacam que a utilização destas favorece um ensino híbrido com maior qualidade. As metodologias ativas vêm ao encontro das necessidades recentes das escolas, de tornar as aulas mais interessantes e modernas, além de possibilitar a descoberta de melhores práticas educativas para facilitar a aprendizagem dos alunos (ALMEIDA et al., 2019). 


\section{Pontos positivos e negativos sobre a implementação do EH}

Os professores foram questionados com base em suas percepções e realidades, sobre os pontos positivos e negativos para implementação do EH em suas escolas. Conforme pode ser observado no Quadro 4, os professores destacam mais pontos negativos do que positivos.

Quadro 4: Percepção dos professores quanto aos pontos positivos e negativos da implementação do ensino híbrido nas suas realidades escolares

\begin{tabular}{|c|c|c|c|}
\hline \multicolumn{2}{|l|}{ Pontos Positivos } & \multicolumn{2}{|l|}{ Pontos Negativos } \\
\hline Categorização & $\%=(77)$ & Categorização & $\%=(77)$ \\
\hline $\begin{array}{l}\text { Maior eficiência na aprendizagem e } \\
\text { promoção de autonomia do aluno }\end{array}$ & $39 \%$ & $\begin{array}{l}\text { Falta de acesso às Tecnologias por } \\
\text { professores e alunos }\end{array}$ & $37,7 \%$ \\
\hline $\begin{array}{l}\text { Fortalecimento do vínculo entre aluno e } \\
\text { professor }\end{array}$ & $27,2 \%$ & Baixo índice de participação dos alunos & $28,6 \%$ \\
\hline $\begin{array}{l}\text { Poucos pontos positivos visto a realidade } \\
\text { socioeconômica dos alunos }\end{array}$ & $13 \%$ & $\begin{array}{l}\text { Falta de estrutura das escolas e formação } \\
\text { docente }\end{array}$ & $7,8 \%$ \\
\hline Sem opinião formada & $13 \%$ & $\begin{array}{l}\text { Medo do contágio nos momentos } \\
\text { presenciais }\end{array}$ & $6,5 \%$ \\
\hline \multirow[t]{3}{*}{$\begin{array}{l}\text { Maior possibilidades no uso de } \\
\text { metodologias diversificadas }\end{array}$} & $7,8 \%$ & Distanciamento entre professor e aluno & $5,2 \%$ \\
\hline & & Baixo poder socioeconômico dos alunos & $3,9 \%$ \\
\hline & & Sem opinião formada & $10,3 \%$ \\
\hline
\end{tabular}

Fonte: as autoras (2021)

$\mathrm{Na}$ categorização dos pontos positivos, a maior parte dos professores citam a eficiência no aprendizado e fortalecimento do vínculo com os alunos, enquanto a maior preocupação relatada nos pontos negativos foi a falta de recursos tecnológicos por parte dos alunos e, em decorrência disso, um baixo índice de participação.

Brito (2020, p. 04) explica que indiferente dos modelos pedagógicos adotados pelo $\mathrm{EH}$, todos eles têm por objetivo "provocar a curiosidade ou de tornar a aprendizagem mais polissêmica". Ainda, Pasin e Delgado (2017) enfatizam sobre o ambiente colaborativo proposto pelo ensino híbrido, que reflete na potencialização da aprendizagem dos alunos. Sobre o EH no atual cenário pandêmico, Oliveira et al. (2021, p. 929) explicam que "vários estudos demonstraram que o ensino híbrido promove aos estudantes maior satisfação e engajamento, devido a maior flexibilidade". Sendo assim, pode-se afirmar, com base nestes estudos, que a aplicação do modelo híbrido de ensino, no atual contexto vivenciado a partir 
da pandemia da Covid-19, apresenta benefícios para os alunos dentro do processo de ensino e aprendizagem.

Quanto aos pontos negativos salientados pelos professores, o ano de 2020 foi de muitos desafios, e um dos principais foi encontrar formas de manter o contato com os alunos. O estudo de Borssoi e Ceron (2020) destacam o retorno de 70\% das atividades encaminhadas aos alunos. Já Nascimento e Peixoto (2015), destacam que essa falta de retorno pode estar associada a fatores socioculturais, atrelados à cultura digital dos sujeitos e ao uso dos recursos tecnológicos, ou ainda, das desigualdades de acesso.

Ainda, sobre os pontos negativos, salienta-se a falta de formação docente na área das tecnologias. Conforto e Vieira (2015) afirmam que a formação tecnológica docente representaria benefícios para o processo de ensino e aprendizagem. Nesse cenário de introdução ao ensino híbrido, tal formação seria imprescindível para garantir a qualidade da implementação. Também pode-se discutir a questão socioeconômica dos alunos, relatada pelos professores. As tecnologias permitem um grande acesso às informações, porém não promovem condições de aprendizagem, quando muitos alunos não têm acesso a elas (DOTTA et al., 2013). Catanante et al. (2020) afirmam, a partir dos resultados de sua pesquisa, que muitos alunos não participam dos momentos e atividades online pois não tem acesso a internet e/ou equipamentos para o momento.

Ao rememorar o conhecimento prévio dos professores sobre metodologias ativas, $88,7 \%$ destacou-se que pouco sabiam sobre estas. Ao final da formação, apesar de ter sido desenvolvida de forma pontual, percebe-se que esta possibilitou um maior entendimento sobre o assunto, além de terem sido disponibilizadas algumas metodologias ativas (Sala de aula invertida, resolução de problemas e Rotação por estações) como formas alternativas viáveis que utilizam de poucos recursos digitais para seu desenvolvimento e combinam com a modalidade híbrida de ensino.

Por fim, ao longo do texto deste artigo foram apresentadas as possibilidades de aprendizagem que o modelo híbrido oferece. Em contrapartida, sabe-se do contexto educacional no qual a Educação Pública Básica está inserida, as constantes mudanças, a desvalorização profissional e as escassas formações continuadas que considerem as necessidades do contexto escolar e que vislumbrem além da teoria, formas práticas de auxiliar os professores nas demandas em sala de aula (SOARES; COPETTI, 2020).

Para uma efetiva implementação dessa modalidade de ensino, como já posto por Lima (2021), requer dedicação, planejamento e uma boa estrutura. Sendo essas 
características, fundamentais para amenizar de alguma forma o problema educacional no qual nosso país enfrenta nesse tempo de pandemia (LIMA, 2021).

Para Lima (2021), de maneira efetiva todas as instituições são passiveis da implementação do ensino híbrido, tanto as que possuem uma infraestrutura tecnológica sofisticada com um grande aparato, bem como as mais carentes e deficitárias, isso também abrange os professores. Entretanto, as escolas que dispõe de menor quantidade de recursos digitais, podem desenvolver projetos que sejam significativos e relevantes para os alunos, visando sempre à ligação dos mesmos com a comunidade, permitindo assim a utilização de tecnologias simples como o celular (LIMA, 2021).

A partir da análise e codificação dos resultados, chega-se à teoria fundamentada dos dados: A implementação do ensino híbrido possibilita a autonomia e maior vínculo com o aluno durante a pandemia, através da interação com tecnologias digitais e diversas possibilidades metodológicas. Tais ações devem ser organizadas de forma flexibilizada, considerando cada contexto escolar, as condições de acesso dos alunos e, carece da responsabilidade das mantenedoras na constante formação docente de seus profissionais, de forma a minimizar as lacunas formativas, e atender de forma mais igualitária a todos os alunos.

De acordo com Cannatá (2017), que estudou a personalização do ensino através do modelo híbrido, a mesma indica a necessidade de valorizar os processos de ensinoaprendizagem de modo a consolidar práticas pedagógicas que migrem para o uso de metodologias ativas. A referida autora observou a necessidade de adaptar o modelo em face das demandas e desafios da contemporaneidade: "é possível colocar o ensino híbrido em prática, por mais que em algumas escolas falte uma cultura escolar ou recursos tecnológicos e sua infraestrutura seja precária" (CANNATÁ, 2017, p. 137).

Ainda que de forma mais trabalhosa, é possível respeitar o ritmo e o tempo do aprendizado de cada aluno, de forma a promover a autonomia, a inclusão e a colaboração, ceder espaço para o protagonismo (do aluno e do professor), melhorar as interações humanas e valorizar a importância do papel do professor em sala de aula como um mediador da aprendizagem, função essa que é insubstituível, independente do modelo de ensino utilizado (CANNATÁ, 2017).

Dentre as possibilidades e dificuldades sobre a implementação do EH, percebe-se professores que o vislumbram como uma forma de se aproximar de forma mais efetiva dos estudantes, outros ainda tem receio desta proximidade, pois a falta de vacina é um risco de contágio em relação ao coronavírus. Independente destas visões, a implementação do ensino 
hibrido precisa respeitar as diferentes realidades escolares, e cabe as instâncias governamentais darem o suporte necessário para uma implementação efetiva, mesmo que adaptada, pois sabe-se das diversas realidades de estudantes sem estrutura mínima necessária para fazer uso desta modalidade.

\section{Considerações finais}

Percebeu-se de acordo com as percepções dos professores, que a implementação do ensino híbrido é viável dentro das realidades escolares onde estes se encontram, visto que este pode possibilitar uma maior aproximação entre professor e aluno, além de oportunizar diferentes métodos de ensino. Em contrapartida, os professores se preocupam em relação às dificuldades de acesso dos alunos aos meios digitais, o medo de contágio relacionado ao coronavírus, a falta de estrutura física das escolas e a necessidade de formação aos professores, bem como o baixo índice de participação dos alunos neste formato.

Salienta-se que os pontos tanto positivos quanto negativos são percepções de professores que ainda não vivenciaram este modelo de ensino. Neste sentido, carece-se de estudos que realizem o acompanhamento destes na imersão do modelo híbrido de forma a auxiliá-los na implementação do mesmo, e, também, reavaliar as percepções iniciais ou ainda, evidenciar resultados diferentes, que sirvam como base para outros professores nas mesmas condições.

Apesar de ser um estudo pautado em pequenas intervenções no contexto dos professores, essa investigação serve de subsídio para elencar elementos que podem ser primordiais na implementação e desenvolvimento do ensino híbrido na rede pública de ensino da fronteira oeste do RS. E ainda, serve como base para evidenciar a necessidade de ações formativas que considerem os anseios dos professores, proporcionem modelos básicos e adaptáveis de propostas híbridas para os diferentes contextos, mas principalmente considerando a pouca estrutura no tocante aos meios digitais.

\section{Referências}

ALMEIDA, C. M.; et al. Propuestas de metodologías activas utilizando tecnologías digitales y herramientas metacognitivas para auxiliar en el proceso de enseñanza y aprendizaje. Revista Paradigma, p. 204-220, 2019.-. https://doi.org/10.37618/PARADIGMA.10112251.2019.p204-220.id748

BACICH, L.; et al. Ensino Híbrido. L. Bacich, A. T. Neto, F. M. Trevisani (editores). Ensino Híbrido: personalização e tecnologia na educação. Porto Alegre: Penso, 2015. 
BACICH, L.; MORÁN, J. Metodologias ativas para uma educação inovadora: uma abordagem teórico prática. Porto Alegre: Penso, 2018.

BERBEL, N. A. N. As metodologias ativas e a promoção da autonomia de estudantes. Ciências Sociais e Humanas. 32 (01). 25-40. 2010. http://dx.doi.org/10.5433/1679$\underline{0383.2011 \mathrm{v} 32 \mathrm{n} 1 \mathrm{p} 25}$

BORSSOI, A. H.; CERON, C. G. S. Estudiantes de los primeros años escolares en tareas matemáticas desde la perspectiva de la Enseñanza Híbrida. PARADIGMA, 353-382, 2020.

BOTTENTUIT JUNIOR, J. B. B. Aplicativos de interação em sala de aula: análise de três possibilidades pedagógicas com recursos digitais. Revista Cocar, 14(30), 2020.

BRASIL. Presidência da República. Decreto n. 9.057 de 25 de maio de 2017. Regulamenta o art. 80 da Lei $n^{\circ}$ 9.394, de 20 de dezembro de 1996, que estabelece as diretrizes e bases da educação nacional. Diário Oficial da União, 2017. Disponível em: http://portal.mec.gov.br/index.php?option $=$ com docman\&view $=$ download\&alias $=652$ 51-decreto9057-pdf\&category slug=maio-2017-pdf\&Itemid=30192

BRASIL. Instituto Nacional de Estudos e Pesquisas Educacionais Anísio Teixeira (INEP). Censo escolar da educação básica. Brasília: INEP. 2019.

BRITO, J. M. S. A singularidade pedagógica do ensino híbrido. EAD em foco, 10(1). 2020.

CANNATÁ, V. M. Ensino híbrido na educação básica: narrativas docentes sobre a abordagem metodológica na perspectiva da personalização do ensino. 158f. Dissertação de mestrado (PPG em Educação) - Universidade Metodista de São Paulo, São Bernardo do Campo. 2017.

CATANANTE, F.et al. Aulas on-line durante a pandemia: condições de acesso asseguram a participação do aluno?. Revista Educ@ção Científica, v. 4, n. 8, p. 977-988, 2020.

CGI. Comitê Gestor da Internet no Brasil-CGI. br. TIC Domicílios 2019. Pesquisa Sobre o Uso das Tecnologias de Informação e Comunicação nos Domicílios Brasileiros-São Paulo: CGI.br. 2019. Disponível em: https://cetic.br/media/docs/publicacoes/2/20201123121817/tic dom 2019 livro eletr onico.pdf

CHARMAZ, K. A construção da teoria fundamentada: guia prático para análise qualitativa. Bookman Editora. 2009.

CONFORTO, D.; VIEIRA, M. C. Smartphone na Escola: Da Discussão Disciplinar Para a Pedagógica. Latin American Journal of Computing, v. II, p. 43-54, 2015.

DOTTA, S. C.; et al. Abordagem dialógica para a condução de aulas síncronas em uma webconferência. In: X Congresso Brasileiro de Ensino Superior à Distância, 2013, Belém. Anais do X Congresso Brasileiro de Ensino Superior à Distância. Belém: Unirede/UFPA, 2013.

FARIAS, D. F. Um relato de experiência: o uso do whatsapp no ensino de fisica durante o isolamento social no colégio estadual do campo de campo formoso. Estudos IAT, 5(3), 307-317, 2020.

FOUREAUX, G.; et al. O ensino-aprendizagem da anatomia humana: avaliação do desempenho dos alunos após a utilização de mapas conceituais como uma estratégia pedagógica. Ciência \& Educação, 24(1), 95-110, 2018. 
GARCIA, T. C. M.; et al. Ensino remoto emergencial: proposta de design para organização de aulas. Monografia (Especialização) - Curso de Educação A Distância, Sedis-ufrn, Universidade Federal do Rio Grande do Norte, Natal, 2020.

GIL, A. C. Métodos e técnicas de pesquisa social. 5. reimpr. São Paulo: Atlas, 2010.

GONÇALVES, A. D. M.; KANAANE, R. A prática docente e as tecnologias digitais. Revista Eletrônica Pesquiseduca, 13(29), 256-265, 2021.

HODGES, C.; et al. As diferenças entre o aprendizado online e o ensino remoto de emergência. Revista da escola, professor, educação e tecnologia, v. 2, 2020.

HORN, M. B; STAKER, H. Blended: usando a inovação disruptiva para aprimorar a educação. Porto Alegre: Penso, 2015.

HUANG K.; et al. Attitudes of Chinese health Sciences postgraduate students' to the use of information and communication technology in global health research. BMC Med Educ. 19(1):367, 2019. http://dx.doi.org/10.1186/ s12909-019-1785-6.

IPEA-Instituto de Pesquisa Econômica Aplicada. Textos para discussão. Professores da Educação básica no Brasil: condições de vida, inserção no mercado de trabalho e remuneração, Brasília, n. 2304, 2017.

JULIANI, D. P.; et al. Utilização das redes sociais na educação: Guia para o uso do Facebook em uma instituição de ensino superior. RENOTE, 10(3), Article 3, 2012. https://doi.org/10.22456/1679-1916.36434

LIMA, J. R. R. A implementação do ensino híbrido no período pós-pandemia. Revista Ibero-Americana de Humanidades, Ciências e Educação, [S. l.], v. 7, n. 2, p. 10, 2021. DOI: $10.51891 /$ rease.v7i2.667.

MACEDO, K. D. S.; et al. Metodologias ativas de aprendizagem: caminhos possíveis para inovação no ensino em saúde. Escola Anna Nery 22(3), 2018.

MANCA, S. Snapping, pinning, liking or texting: Investigating social media in higher education beyond Facebook. The Internet and Higher Education, 44, 100707, 2020. https://doi.org/10.1016/j.iheduc.2019.100707

MASETO, M. T. O professor na hora da verdade. São Paulo: Avercamp, 2010.

MIRANDA, R. V.; et al. Ensino Híbrido: Novas Habilidades Docentes Mediadas pelos Recursos Tecnológicos. EaD em Foco. 10(913). 2020. DOI: https://doi.org/10.18264/eadf.v10i913

MITRE, S. M.; et al. Metodologias ativas de ensino-aprendizagem na formação profissional em saúde: debates atuais. Ciência \& saúde coletiva, 13, 2133-2144, 2008. http://dx.doi.org/10.1590/S1413-81232008000900018

MORAIS, A. P. M.; SOUZA, P. F. Formação docente continuada: ensino hibrido e sala de aula invertida como recurso metodológico para o aprimoramento do profissional de educação. Devir Educação, 10-32, 2020.

MORAN, J. (2018). Metodologias ativas para uma aprendizagem mais profunda. Metodologias ativas para uma educação inovadora: uma abordagem teórico-prática. Porto Alegre: Penso, 2018. Recuperado de http://www2.eca.usp.br/moran/wpcontent/uploads/2013/1 2/metodologias_moran1.pdf

MORAN, J. Educação Híbrida. L. Bacich, A. T. Neto, F. M. Trevisani (editores). Ensino Híbrido: personalização e tecnologia na educação. (244) Porto Alegre: Penso, 2015. 
NASCIMENTO, N. A.; PEIXOTO, J. Mídias digitais e desenvolvimento infantil: Para além de rótulos e explicações. Série-Estudos-Periódico do Programa de Pós-Graduação em Educação da UCDB, 40, 119-138, 2015. https://www.serie-estudos.ucdb.br/serieestudos/article/view/872

NETO, E. B. O ensino híbrido: processo de ensino mediado por ferramentas tecnológicas. Ponto-e-Vírgula: Revista de Ciências Sociais, (22), 59-72, 2017. doi.org/10.34117/bjdv7n1-061

NOVAIS, I. A. M. Ensino híbrido: estado do conhecimento das produções científicas no período de 2006 a 2016.143f. Dissertação (Mestrado em Educação) - Universidade Estadual de Maringá, Paraná, 2017.

OLIVEIRA, M. B.; et al. O ensino híbrido no Brasil após pandemia do covid-19. Brazilian Journal of Development, 7(1), 918-932, 2021.

PASIN, D. M.; DELGADO, H. O. K. O ensino híbrido como modalidade de interação ativa e reflexão crítica: relato de uma experiência docente no Brasil. Texto Livre: Linguagem e Tecnologia, 10(2), 87-105, 2017. https://doi.org/10.17851/1983-3652.10.2.87-105

PIFFERO, E. D. L. F.; et al. Metodologias Ativas e o ensino de Biologia: desafios e possibilidades no novo Ensino Médio. Ensino \& Pesquisa. 18(02), 48-63, 2020. https://doi.org/10.33871/23594381.2020.18.2.48-63

PONTES, A. F.; BARBOZA, P. O professor de matemática frente às tecnologias e as dificuldades em integrá-las na sala de aula. Ensino Em Foco, 3(8), 33 - 47, 2021.

RODRIGUES, E. F. A questão da verificação de aprendizagem no modelo de ensino híbrido. L. Bacich, A. T. Neto, F. M. Trevisani (editores). Ensino Híbrido: personalização e tecnologia na educação. (244) Porto Alegre: Penso, 2015.

SCHIEHL, E. P.; GASPARINI, I. Modelos de ensino híbrido: Um mapeamento sistemático da literatura. In Brazilian Symposium on Computers in Education (Simpósio Brasileiro de Informática na Educação-SBIE) (Vol. 28, No. 1, p. 1), 2017.

SCHNEIDER, F. Otimização do espaço escolar por meio do modelo de ensino híbrido. L. Bacich, A. T. Neto, F. M. Trevisani (editores). Ensino Híbrido: personalização e tecnologia na educação. (244) Porto Alegre: Penso, 2015.

SCORSOLINI-COMIN, Fabio. Psicologia da educação e as tecnologias digitais de informação e comunicação. Psicologia Escolar e Educacional, v. 18, n. 3, p. 447-455, 2014.

SILVA, A. H.; VILHEGAS, V. P. (2013). IHC em dispositivos móveis - análise do aplicativo whatsapp. In: Encontro de iniciação científica das faculdades integradas "Antonio Eufrásio de Toledo", 9, Presidente Prudente, SP. Anais... FIAET, n.24-25, p.1-13, set, 2013.

SILVA, A. J. F.; et al. A adesão dos alunos às atividades remotas durante a pandemia: realidades da educação física escolar. Corpoconsciência, 24(2), 57-70, 2020.

SILVA, M. M. A. Formação continuada de professores e tecnologia: concepções docentes, possibilidades e desafios do uso das tecnologias digitais na educação básica (Master's thesis, Universidade Federal de Pernambuco), 2014.

SOARES, R. G.; COPETTI, J. Formação profissional docente: perfil e compreensão de professores de uma escola pública do RS. Práxis Educacional, 16(40), 573-591, 2020. https://doi.org/10.22481/praxisedu.v16i40.6446 
SOUZA, T. M., et al. Ensino híbrido: Alternativa de personalização da aprendizagem. Revista Com Censo, Brasília, n.16, v.6, n.1, p.55-66, 2019.

SPINARDI, J. D.; BOTH, I. J. Blended learning: o ensino híbrido e a avaliação da aprendizagem no ensino superior. Boletim técnico do senac, 44(1), 2018.

VALENTE, J. A. Blended learning e as mudanças no ensino superior: a proposta da sala de

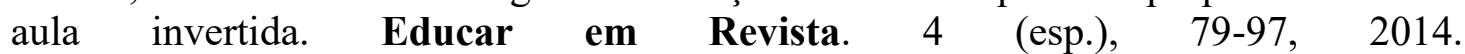
http://dx.doi.org/10.1590/0104-4060.38645

\section{Autores:}

Renata Godinho Soares ${ }^{(*)}$

Mestre no Programa de Pós-Graduação em Educação em Ciências: Química da Vida e Saúde e especialista em Atividade Física e Saúde pela Universidade Federal do Pampa -

Campus Uruguaiana. Pesquisadora no Grupo de Estudos e Pesquisa em Estágio e Formação de Professores (GEPEF), UNIPAMPA-Uruguaiana. Licenciada em Educação Física pela Universidade da Região da Campanha - Campus Alegrete. renatasoares.aluno@unipampa.edu.br http://orcid.org/0000-0002-2386-2020

Universidade Federal do Pampa (UNIPAMPA) - Uruguaiana, Brasil.

Caroline Pugliero Coelho ${ }^{(*)}$

Mestre do PPG Educação em Ciências: Química da Vida e Saúde da Universidade Federal do Pampa (UNIPAMPA Campus Uruguaiana). Especialista em Neuropsicopedagogia Clínica (2013) e em Gestão Escolar (Administração, Supervisão e Orientação) (2014) pelo Grupo UNIASSELVI. Graduada em Ciências Biológicas pela Universidade da Região da Campanha (Campus Alegrete) (2010). Atuante na EMEB Eurípedes Brasil Milano. carolinecoelho.aluno@unipampa.edu.br http://orcid.org/0000-0003-2999-9316

Eliane de Lourdes Fontana Piffero ${ }^{(*)}$

Possui graduação em Ciências Biológicas pela Universidade da Região da Campanha (1996), especialista em Educação Ambiental pela Universidade da Região da Campanha (2000), mestrado em Docência Universitária pela Universidade Tecnológica Nacional(UTN) de Buenos Aires (2010) e mestrado em Ensino de Ciências pela Universidade Federal do Pampa (2017). Atualmente é professora na rede pública do estado do RS e na Universidade da Região da Campanha. elianepiffero.aluno@unipampa.edu.br http://orcid.org/0000-0001-7817-3903

Jaqueline Copetti (*)

Possui Licenciatura Plena em Educação Física pela Universidade Federal de Santa Maria (2003), Especialização em Ciência do Movimento Humano pela UFSM (2005), Mestrado em Educação Física pela Universidade Federal de Pelotas (2009) e Doutorado em

Educação em Ciências: Química da Vida e Saúde pela UFSM (2013). Professora do Magistério Superior da Universidade Federal do Pampa, lotada no Campus Uruguaiana. Líder do Grupo de Estudos e Pesquisa em Estágio e Formação de Professores - GEPEF. jaquelinecopetti@unipampa.edu.br https://orcid.org/0000-0003-4838-1810

(*) Universidade Federal do Pampa (UNIPAMPA) Uruguaiana, Brasil 